\title{
da
}

DA, n², enero-diciembre 2015, ISSN: 1989-8983

\section{LA POTESTAD SANCIONADORA DE LA ADMINISTRACIÓN: UNA REGULACIÓN FRAGMENTARIA, INCOMPLETA Y PERNICIOSA}

\author{
Tomás Cano Campos \\ Universidad Complutense de Madrid \\ tcano@der.ucm.es
}

1.

En la fase última de la legislatura de forma totalmente innecesaria y apresurada y sin el necesario reposo, tiempo y reflexión que requiere la elaboración de dos normas de tanta envergadura, se siguen tramitando en las Cortes Generales los proyectos de Ley de Régimen Jurídico del Sector Público y de Procedimiento Administrativo Común de las Administraciones Públicas que, según parece, y a partir del momento de su entrada en vigor, van a regular, entre otras muchas cuestiones, la potestad sancionadora de las Administración Públicas. Estas dos normas no sólo resultan totalmente innecesarias, dado su contenido refundidor y, en ocasiones, disgregador de las normas ya existentes, sino que, además, es sumamente criticable el procedimiento puramente burocrático que se ha seguido para su elaboración.

Con relación al procedimiento que se ha utilizado para preparar los dos textos, puede hacerse el mismo juicio crítico que se hizo respecto de la vigente Ley 30/1992, de 26 de noviembre, de Régimen Jurídico de las Administraciones Públicas y el Procedimiento Administrativo Común (LRJPAC): "Profesores, jueces, abogados, funcionarios, integrados en una comisión técnica y responsable no hubiesen sido aquí los depositarios de ningún saber sacerdotal; son, simplemente, los que conocen cómo funciona el sistema y cuáles son sus aciertos y sus posibles deficiencias, cómo unos preceptos se interrelacionan con otros y entre todos constituyen un sistema. Ello sin perjuicio, naturalmente, de que los políticos, como está justificado en su titularidad pública, marquen las grandes líneas de desarrollo convenientes y acepten o no las indicaciones de los técnicos"”.

En la elaboración de ambos textos, se ha prescindido también de la sección de Derecho público de la Comisión General de Codificación. Para una reforma de menor entidad, sin embargo, por Orden de 11 de julio de 2012 se creó en el seno de dicha Comisión una sección especial para la reforma de la Ley de la Jurisdicción Contencioso-Administrativa, integrada por diversos profesionales del Derecho Público y de dicho orden jurisdiccional. La Sección especial estaba formada, en concreto, por tres catedráticos de Derecho Administrativo, tres abogados del Estado, un miembro del Cuerpo Superior de Administradores Civiles del Estado y cinco magistrados, además de por un grupo de apoyo de profesores de Derecho público expertos en Derecho comparado. La sección, fruto de esa diversidad profesional, elaboró un Informe explicativo y una interesante propuesta de anteproyecto de ley de eficiencia de la Ley de la Jurisdicción Contencioso-Administrativa, que publicados ambos por el Ministerio de Justicia en marzo de 2013. La reciente e importante reforma del recurso de casación en la LJCA llevada a cabo por la Disposición final $3^{\text {a }}$ de Ley orgánica 7/2015, de 21 de julio, por la que se modifica la Ley orgánica del Poder Judicial, está directamente basada en la propuesta realizada y publicada por la referida Sección Especial de la Comisión de Codificación.

Lamentablemente, en la elaboración de los dos proyectos de Ley en tramitación tampoco se han aprovechado los interesantes informes elaborados por el Grupo de Expertos para el Estudio de las Principales Líneas de Reforma de las Administraciones Públicas, creado por la Orden de 25 de Abril de 2003, y presidido el profesor Fernando Sainz Moreno, cuyos trabajos publicó en su integridad el Instituto Nacional de Administración Pública en abril 2004 y donde se tratan muchos de los temas que regulan expresamente los dos proyectos de Ley que nos ocupan: organización, tecnologías de la información, potestad sancionadora de las Administraciones Públicas, su sistema de responsabilidad patrimonial, controles sobre la actuación de las Administraciones Públicas, etc.

1 E. GARCíA DE ENTERRÍA, “Un punto de vista sobre la nueva Ley de Régimen Jurídico de las Administraciones Públicas y del procedimiento administrativo común de 1992", en J. LEGUINA VILLA y M. SÁNCHEZ MORÓN (directores), La nueva Ley de Régimen Jurídico de las Administraciones Públicas y del Procedimiento Administrativo Común, Madrid, Tecnos, 1993, p. 12 
2.

La Exposición de Motivos de uno de los textos, en concreto la del proyecto de Ley de Régimen Jurídico del Sector Público, señala que ambos textos obedecen a la necesidad, apreciada por la Comisión para la reforma de las Administraciones públicas en su informe de 21 de junio de 2013, "de dotar a nuestro sistema legal de un Derecho Administrativo sistemático, coherente y ordenado". Pero, para satisfacer tal necesidad, lo mejor hubiera sido aprobar un Código de las Administraciones Públicas o un Código Administrativo, donde se recojan las normas básicas, o la mayor parte de las Administraciones Públicas; Código que el Estado puede aprobar al amparo del art. 149.1.18 ${ }^{a}$ de la Constitución: bases del régimen jurídico, procedimiento administrativo común, potestad sancionadora, sistema de responsabilidad de las Administraciones Públicas, legislación básica sobre contratos y concesiones, subvenciones, expropiación.

Desde luego que con los dos proyectos que ahora se presentan, y que parece que se van a aprobar antes de que concluya la legislatura, no se logra en absoluto ese objetivo, sobre todo en lo que se refiere a la regulación de dos instituciones tan importantes para el Derecho Administrativo, y que gozan de un expreso reconocimiento constitucional, como son la potestad sancionadora y al sistema de responsabilidad de nuestras Administraciones Públicas. Aparte de que no se ha tenido en cuenta todo lo decidido por la jurisprudencia y lo escrito por la doctrina para alcanzar una regulación completa y acabada de tales instituciones, incomprensiblemente se reproduce casi miméticamente la regulación actual de la LRJPAC, pero de forma dispersa y fragmentada en los dos nuevos proyectos: la parte sustantiva o material de las sanciones administrativas y de la responsabilidad patrimonial de la Administración en el proyecto de Ley de Régimen Jurídico del Sector Público, en concreto en el Título preliminar, justo después de los órganos colegiados; la parte procedimental de ambas instituciones, en el proyecto de Ley de Procedimiento Administrativo Común de las Administraciones Públicas, pero diseminada y dispersa en la regulación de las diversas fases del procedimiento administrativo común. Se trata de dos instituciones nucleares cuya regulación no se debería fragmentar por el prurito de mantener la absurda distinción entre cuestiones organizativas y bien procedimentales (en las que, como dice el Consejo de Estado en sus dictámenes a ambos proyectos, no encajan la potestad sancionadora y la responsabilidad patrimonial), sino que más bien deberían ser objeto de regulación en un solo cuerpo legal o, mejor aún, en un texto independiente que regule de forma completa tan importantes instituciones. Un texto que, de paso, contenga de forma completa y sistemática la regulación de una y otra sobre la base de la experiencia práctica, la doctrina jurisprudencial y los numerosos escritos doctrinales de todos estos años, que son numerosos e importantes en el marco de ambas instituciones. En esta breve comunicación me centraré únicamente en las carencias y deficiencias que presenta la regulación de la potestad sancionadora de la Administración en ambos proyectos.

3.

La potestad sancionadora de la Administración no debe estar regulada en dos textos normativos distintos y, menos aún, de forma fragmentaria y parcial. Esta potestad, al igual que el sistema de responsabilidad de las Administraciones Públicas, debería haberse regulado en un solo texto o disposición normativa y, como se ha adelantado, de forma completa y sistemática y no, como se hace, con carácter fragmentario o parcial, con la merma para la seguridad jurídica que ello supone. Incluso estaría justificada su regulación en una sola Ley, como ocurre en otros países (Alemania e Italia), quizá junto a otra importante y olvidada institución como la inspección administrativa². Es claro que al amparo del art. 149.1.18 $\mathrm{CE}$, el Estado está habilitado para aprobar una ley general y básica sobre la potestad inspectora y sancionadora de la Administración.

Como es bien sabido, la regulación actual de la potestad sancionadora en la LRJPAC se limita a recoger las exigencias de las sanciones que el TC ha deducido de los artículos 25 y 24.2 de la Constitución. Esta escueta regulación de las sanciones administrativas en nuestro país, que ahora se reproduce esparcida por los dos proyectos señalados, resulta claramente insuficiente y hasta perniciosa o perjudicial por varias razones, que paso a exponer brevemente?

En primer lugar, la regulación de la LRJPAC resulta claramente insuficiente para resolver los numerosos problemas que plantea diariamente la potestad sancionadora de la Administración. El Código Penal dedica más de

2 Sobre el tema, vid. J. J. DíEZ SÁNCHEZ (coordinador), Función Inspectora (Actas del VIII Congreso de la Asociación Española de Profesores de Derecho Administrativo, celebrado en Alicante en febrero de 2013), Madrid, INAP, 2013.

3 Lo mismo puede decirse en relación a una institución también capital como la responsabilidad patrimonial de las Administraciones Públicas, que es una garantía esencial de los ciudadanos, pero también un cauce capital para controlar el funcionamiento de los servicios públicos. Una regulación como la vigente y la que de forma dispersa se reproduce en los dos proyectos de ley, sigue estando formada por una serie de disposiciones demasiado vagas e imprecisas que no regulan adecuadamente una realidad tan compleja y, lo que es peor, no solucionan la mayoría de los problemas diarios con que se enfrentan los particulares, la Administración y los Tribunales. Pondré sólo un ejemplo: la ley, a la que remite el artículo 106 de la Constitución, sigue sin aclarar cuando responde la Administración por el funcionamiento normal de los servicios públicos y cuando surge la responsabilidad por el funcionamiento anormal. 
cien artículos a la parte general del Derecho penal, mientras que la LRJPAC sólo le dedica a las cuestiones generales del Derecho Administrativo Sancionador seis escuetos preceptos, a pesar de que éste es mucho más extenso que aquél debido a que las sanciones administrativas se ha convertido hoy en el refuerzo de la gestión ordinaria de la Administración o, más exactamente, en el respaldo de las políticas públicas de intervención. En la LRJPAC, y en los dos proyectos actuales, falta, además, como vamos a ver de inmediato, una regulación de cuestiones tan básicas y esenciales en el orden material de la potestad sancionadora de la Administración como los distintos tipos de sanciones, las causas de justificación, las atenuantes y agravantes, los sujetos responsables, la mayoría de edad, el tratamiento del error y sus tipos, las causas de extinción de la responsabilidad sancionadora, etc. En algunas cuestiones, la LRJPAC está innecesariamente apegada al Derecho penal, por ejemplo, en la aplicación de la retroactividad in bonus. Faltan también en la Ley actual y en los proyectos que la sustituyen numerosísimas e importantes cuestiones procedimentales que una Ley general o completa en la materia también debería recoger y de las que el nuevo proyecto de Ley de Procedimiento Administrativo Común tampoco se ocupa.

En segundo lugar, la distinta posición entre la Jurisdicción y la Administración y las diferencias estructurales entre una y otra hacen también necesaria la aprobación de un texto más completo o de una Ley general sobre la potestad sancionadora de las Administraciones Públicas; una texto que recoja soluciones específicas para un sujeto especial como la Administración, que no es neutral como el juez, por mucho que persiga, o deba perseguir con objetividad, los intereses generales.

La actual regulación resulta perniciosa, por último, porque su insuficiencia está abocando a un casuismo jurisprudencial indeseable, así como a la heterogeneidad y dispersión normativa del Derecho administrativo sancionador. La ausencia de una regulación común en la materia no sólo es una incitación a que el legislador autonómico y el poder local establezcan regulaciones individualizadas, sino también, y sobre todo, a que el propio legislador estatal establezca regímenes sancionadores singulares en los distintos sectores de intervención. Al punto que, incluso, cabe plantearse si puede hablarse hoy de un solo Derecho administrativo sancionador y no de tantos Derechos sancionadores como sectores ordinamentales con características singulares hay (fiscal, social, tráfico, policía, medioambiente, urbanismo, sanitario, etc.), de modo que es preciso un sistema conceptual y normativo que integre, homogeneice y coordine el funcionamiento de todos estos regímenes positivos que se entrecruzan territorial y materialmente ${ }^{4}$.

El legislador estatal debería haber acometido, de una vez por todas, la tarea de aprobar una Ley general sobre la potestad sancionadora de la Administración que, además de los principios por los que ha de regirse, ofrezca un cuadro legislativo homogéneo y general de las infracciones y sanciones y regule los elementos esenciales del procedimiento administrativo sancionador; en definitiva, lo que debiera ser una parte general del Derecho administrativo sancionador. Una parte general que debería regular con flexibilidad tales cuestiones, permitiendo que la legislación sectorial pueda incluir las especialidades necesarias en aquellos aspectos no necesitados de una regulación uniforme. La tarea es perfectamente posible, como bien demuestra la Ley sobre la potestad sancionadora del País Vasco de 1998.

4.

Los proyectos de ley en tramitación han obviado todos estas cuestiones por completo. A parte de la incomprensible fragmentación del régimen jurídico de esta institución, desoyendo por completo la recomendación del Consejo de Estado, no se entiende por qué se incluyen ahora en los dos proyectos unas cosas y no otras 5 .

Faltan en los proyectos aspectos básicos y nucleares de la potestad sancionadora de la Administración como los elementos esenciales de las infracciones. Ahora se incluye expresamente la necesidad de que los hechos constitutivos de infracción administrativa se realicen de forma dolosa o culposa (artículo 28, del anteproyecto de Ley

4 A. Nieto García, Derecho administrativo sancionador, $5^{\text {a }}$ ed., Madrid, Tecnos, 2012, pp. 569-570.

5 El Dictamen del Consejo de Estado, de 29 de abril de 2015, al Anteproyecto de Ley de Procedimiento Administrativo Común de las Administraciones Públicas, destaca la necesidad de una "regulación íntegra y ordenada del régimen jurídico de la potestad sancionadora y la responsabilidad patrimonial de las Administraciones Públicas en su dimensión constitucionalmente garantizada, tal y como actualmente sucede con la Ley 30/1992; o, en caso de que se mantenga el enfoque actual [que utiliza como criterio de delimitación de uno y otro anteproyecto las nociones de organización y procedimiento, a ninguna de las cuales se ajusta con exactitud la potestad sancionadora y la responsabilidad], se remita la disciplina de la potestad sancionadora y de la responsabilidad de las Administraciones Públicas a leyes singulares y distintas de los anteproyectos en cuestión". El dictamen, de la misma fecha, sobre el Anteproyecto de Ley de Régimen Jurídico del Sector Público incide en la misma idea y critica la regulación separada de otras materias como los órganos colegiados o el uso de medios electrónicos. Como se sabe, en los anteproyectos de ley, la potestad sancionadora y la responsabilidad de la Administración se regulaban de forma conjunta, como procedimientos especiales, en el Anteproyecto de la Ley de Procedimiento Administrativo, lo que fue duramente criticado por el Consejo de Estado en tales dictámenes porque, obviamente, tales instituciones no son “especialidades del procedimiento administrativo". Para eludir esta crítica, los proyectos actuales incurren en un defecto aun mayor: la disgregación en dos textos de la regulación de ambas instituciones obviando así que, en opinión del propio Consejo de Estado, han de estar en una sola norma o en una ley especial ad hoc. 
de régimen jurídico del sector público, relativo a la responsabilidad por la comisión de infracciones), pero no se dice nada acerca del error y sus modalidades (error de tipo y error de prohibición, error vencible o invencible) o de las consecuencias que acarrea incurrir en uno u otro tipo de error. Dicho precepto establece que serán responsables las personas físicas y jurídicas y, cuando la ley les reconozca capacidad de obrar, los grupos de afectados, las uniones y entidades sin personalidad y los patrimonios autónomos o independientes (artículo 28 del mismo anteproyecto), pero ni siquiera se establece el concepto de autor o la responsabilidad o no de los cómplices.

Los Proyectos siguen sin aclarar también una cuestión tan importante y esencial como la edad a partir de la cual la Administración puede sancionar. La doctrina hace ya tiempo que demandó "criterios claros y elementales" que resuelvan este problema ${ }^{6}$. Pero nuestro Derecho sigue guardando en general silencio sobre el tema. En otros Derechos, como el alemán y el italiano, se establece con carácter general la edad de catorce y dieciocho años, respectivamente. Esta última es la edad que rige en materia penal tras el nuevo Código de 1995, si bien el menor de dieciocho años que cometa un hecho delictivo podrá ser responsable con arreglo a lo dispuesto en la Ley de responsabilidad penal del menor, que se aplica a partir de los catorce años (art. 19). Alguna ley sectorial reciente, como la Ley orgánica 4/2015, de 30 de marzo, de protección de la seguridad ciudadana, se ocupa del tema y dispone que están exentos de responsabilidad por las infracciones cometidas en ese sector los menores de catorce años (artículo 30.2). La Ley de la Potestad sancionadora del País Vasco de 1998, como en otras muchas cuestiones, podría haber servido de modelo, pues, con buen criterio, dispone que "las normas sancionadoras sectoriales, en atención a la naturaleza y finalidad de la concreta regulación material sectorial de que se trate y a la capacidad de obrar que en dicha regulación se reconozca a los menores, fijarán el límite de edad a partir del cual se puede ser responsable de una infracción. A falta de disposición al efecto, no serán responsables los menores de 14 años" (art. 6.3). Cuestión distinta, y muy importante, son las sanciones que cabe imponer a los menores de cierta edad, que también debería ser objeto de una regulación expresa con carácter general. Como con toda razón han señalado ya algunos autores, sería deseable prever un tipo de sanciones específicas para los menores de edad, pues parece evidente que la sanción pecuniaria no resulta la más adecuada para las infracciones cometidas por los menores, pudiendo resultar más eficaces y, sobre todo, más acordes con los propios intereses de los menores las sanciones de finalidad o contenido educativo.

Tampoco se regulan las causas de exclusión de la antijuridicidad (causas de justificación) y de la culpabilidad (causas de inimputabilidad), como tampoco se establece el momento en que se han de entender cometidas las infracciones o quién debe sancionar las infracciones suprarregionales, que tienen una indudable importancia práctica en ámbitos como el del comercio interior y el consumo.

Los proyectos no ofrecen siquiera un cuadro mínimo y general de las sanciones administrativas y de su contenido y extensión, de modo que cada ley sectorial contempla o inventa las que considera adecuadas para el sector de que se trate. La regulación de los concursos, de normas y de infracciones, no está bien ubicada sistemáticamente y, además, es parcial. El artículo 29 del Proyecto de Ley de Régimen Jurídico del Sector Público, que se ocupa del principio de proporcionalidad, regula en sus apartados 5 y 6 , el concurso medial de infracciones (una infracción es un medio para cometer otra) y las infracciones continuadas, pero no se ocupa, ni en ese ni en ningún otro precepto, del concurso ideal de infracciones (hay una pluralidad de infracciones que derivan de un solo hecho) ni del concurso de normas administrativas (un determinado hecho realiza el supuesto de hecho de dos o más normas administrativas por sólo una de ellas debe aplicarse porque basta por sí misma para abarcar el total desvalor del hecho) ni, desde luego, de las sanción o sanciones que, en tales casos, debe aplicarse.

El proyecto de Ley de Régimen Jurídico del Sector Público, como tantas otras leyes sectoriales, sólo regula como forma de extinción de la responsabilidad la prescripción de las infracciones y de las sanciones, como si fuera la única causa por la que se extingue la responsabilidad en el ámbito sancionador. Nada se dice de otras formas de extinción como la muerte de la persona física, la disolución de la jurídica, la condonación de las sanciones, etc. La Ley vasca citada establece una regulación completa de la materia. Según su art. 19, la responsabilidad se extingue: “a) Por la muerte de la persona física sancionada; b) Por la ejecución completa de la sanción; c) Por el indulto; d) Por la prescripción de la infracción; e) Por la prescripción de la sanción. 2. En los casos de extinción de la persona jurídica sancionada, para la ejecución de la sanción o sanciones se estará a lo que dispongan las normas administrativas sectoriales o la normativa de Derecho privado que resulte aplicable".

La regulación del procedimiento sancionador también es incompleta y deficiente en el proyecto de Ley de Procedimiento Administrativo Común. El proyecto incluye prácticamente el contenido del reglamento para el ejercicio de la potestad sancionadora de la Administración de 4 de agosto de 1993 que hasta ahora era supletorio. Este

6 L. MARtín-Retortillo Baquer, “Multas administrativas”, en Revista de Administración Pública núm. 79, 1976 , pp. 45-46. 
reglamento quizá no debería ser supletorio en su totalidad, pero parte de su regulación tampoco parece propia de una Ley (por ejemplo, la definición de denuncia, de orden superior, de petición razonada, etc.).

El proyecto de Ley de Procedimiento Administrativo Común no se ocupa tampoco de una cuestión de enorme interés como la relativa a si la Administración tiene o no la obligación de iniciar un procedimiento sancionador y, en su caso, de sancionar cuando tiene conocimiento de unos hechos constitutivos de infracción administrativa, esto es, si rige en la materia del principio de legalidad o el de oportunidad. Aunque al respecto no hay un consenso doctrinal y jurisprudencial sobre esta cuestión, el proyecto de ley debería haber dado un paso y establecer algunos criterios que le permitan a la Administración, en función de los medios con los que cuenta en cada momento y sector para reprimir las infracciones, valorar el momento en que comenzar a sancionar (sobre todo cuando hay un cambio normativo o tiene lugar la entrada en vigor de una nueva norma), respetar en su ejercicio el principio de igualdad, etc.

En el ámbito procedimental, sigue sin determinarse también quién tiene la carga de la prueba de las circunstancias eximentes o que pueden excluir la responsabilidad (¿recae sobre el imputado o si éste las alega debe probar la Administración que no concurren?), o cómo se ha de practicar en la prueba testifical, el interrogatorio de los presuntos responsables de la infracción o la prueba pericial, para lo cual quizá sea conveniente inspirarse más en el proceso penal que en el civil, etc. Se hecha en falta, también, una regulación detallada de las medidas provisionales que, además de asegurar la eficacia de la resolución sancionadora, cumpla otras funciones en el procedimiento sancionador como evitar que se repita la infracción o se siga cometiendo o se mantengan los efectos de la ya consumada 7 . La solución actual de la caducidad tampoco es satisfactoria ya que se permite que se pueda iniciar un nuevo procedimiento aunque el primero haya caducado si la infracción aún no ha prescrito (art. 95.3 del proyecto de Ley de Procedimiento Administrativo Común). La solución en este ámbito de la Ley General Tributaria, prohibiendo esa posibilidad (artículo 211.4)., se acomoda mejor al carácter y a la finalidad de las sanciones administrativas.

No está justificado que en el proyecto se siga excluyendo los procedimientos sancionadores en materia tributaria y aduanera, en el orden social, en materia de tráfico y seguridad vial y en extranjería (Disposición Adicional $\left.1^{2}\right)$, pues ni está claro ni se aclara cuál es el criterio para excluir estos y no otros sectores. Sería más razonable y ponderada una solución en la que la ley general estableciera un marco procedimental común pero dúctil o flexible que permitiera que esas u otras leyes establecieran algunas especialidades procedimentales justificadas en la singularidad de la materia.

\section{5.}

Con relación a la potestad sancionadora de las Administraciones Públicas, en definitiva, falta en los proyectos en tramitación un auténtico régimen jurídico común y, por ello, un sistema completo, coherente y flexible de las infracciones y sanciones administrativas en el que descansen las diversas leyes sectoriales sin necesidad de abordar casuísticamente los problemas sectoriales diarios o de abandonarlos a las soluciones particulares de la jurisprudencia. Por eso, lamentablemente, se ha perdido una vez más una gran oportunidad. Los casi trienta años transcurridos desde la aprobación de la Constitución parecen no haber servido de nada en este sector. Afortunadamente las Disposiciones finales de los referidos proyectos establecen que, cuando se aprueben, ambas leyes entrarán en vigor al año de su publicación. Al menos queda el consuelo de que, si finalmente son aprobadas y publicadas en el Boletín Oficial del Estado, todavía habría tiempo para que el próximo legislador reflexione seriamente sobre la verdadera necesidad de tales leyes y reconsidere por completo el planteamiento adoptado desde el punto de vista sistemático y muchas de las soluciones materiales adoptadas antes de que entren en vigor.

7 Sobre estas y otras cuestiones destacadas en el texto, vid. el interesante informe de M. REBOLLO PUIG, "Propuesta de regulación general y básica de la inspección y de las infracciones y sanciones administrativas", en F. SAINZ MoRENo (director), Estudios para la reforma de la Administración Pública, Madrid, INAP, 2004, pp. 447-475. 